\title{
RESEARCH
}

Open Access

\section{Current practices and perceived implementation barriers for working with alcohol prevention in occupational health services: the WIRUS OHS study}

Mikkel Magnus Thørrisen ${ }^{1,2^{*}}$ D, Jens Christoffer Skogen ${ }^{3,4,5}$, Ingvild Kjeken ${ }^{1,6}$, Irene Jensen ${ }^{7}$ and Randi Wågø Aas ${ }^{1,2,5}$

\begin{abstract}
Background: Alcohol is associated with detrimental health and work performance outcomes, and one to three out of ten employees may benefit from interventions. The role of occupational health services (OHS) in alcohol prevention has received little attention in research. The primary aims of this study were to explore current practices of alcohol prevention targeting employees in occupational health settings, and examine whether and which perceived implementation barriers were associated with alcohol prevention activity. The secondary aim was to explore whether barriers were differentially associated with primary, secondary and tertiary prevention activities.

Methods: In this cross-sectional study, survey data were collected from 295 OHS professionals in Norway in 2018. Data were analysed by means of descriptive statistics, one-way analysis of variance, paired samples t-tests, and multivariate linear regression analyses.

Results: Overall, seven out of ten OHS professionals worked with alcohol-related cases less than monthly, while only one out of ten did so on a weekly basis. Their activities were more focused on tertiary prevention than on primary and secondary prevention. Physicians, psychologists and nurses reported to handle alcohol-related issues more often than occupational therapists and physical therapists. Higher levels of implementation barriers internal to the OHS' organisation (competence, time and resources) were associated with lower alcohol prevention activity. Barriers external to the OHS' organisation (barriers concerning employers and employees) were not. This pattern was evident for primary, secondary and tertiary prevention activities. A majority of OHS professionals agreed that employees' alcohol consumption constitute a public health challenge, and that OHS' should focus more on alcohol prevention targeting employees.

(Continued on next page)
\end{abstract}

\footnotetext{
* Correspondence: mikkel-magnus.thorrisen@oslomet.no

'Department of Occupational Therapy, Prosthetics and Orthotics, Faculty of

Health Sciences, OsloMet - Oslo Metropolitan University, PO box 4 St. Olavs

plass, NO-0130 Oslo, Norway

${ }^{2}$ Presenter - Making Sense of Science, PO box 8118, NO-4068 Stavanger,

Norway

Full list of author information is available at the end of the article
}

(c) The Author(s). 2019 Open Access This article is distributed under the terms of the Creative Commons Attribution 4.0 International License (http://creativecommons.org/licenses/by/4.0/), which permits unrestricted use, distribution, and reproduction in any medium, provided you give appropriate credit to the original author(s) and the source, provide a link to the Creative Commons license, and indicate if changes were made. The Creative Commons Public Domain Dedication waiver (http://creativecommons.org/publicdomain/zero/1.0/) applies to the data made available in this article, unless otherwise stated. 
(Continued from previous page)

Conclusions: Occupational health settings at workplaces may be particularly serviceable for alcohol prevention programmes since the majority of the population is employed and the majority of employees consume alcohol. An increase in overall prevention activity, and a shift from mainly focusing on tertiary prevention to an increased emphasis on primary and secondary prevention, may both hinge on increased training of OHS professionals, emphasising knowledge on the importance of working with alcohol prevention, and training in administering alcohol prevention programmes. Making alcohol prevention a priority may also require increased allocation of time and resources.

Keywords: Alcohol consumption, Occupational health services, Workplace interventions, Workforce, Implementation, Prevention

\section{Background}

Occupational health services (OHS) aim to protect and promote employees' safety and health, as well as to improve the work environment and working conditions [1-3]. The majority of the population is employed and the majority of employees consume alcohol. Therefore, several researchers have argued that the OHS should be more actively involved in alcohol prevention targeting employees [1, 4-6]. It has proved feasible to conduct brief alcohol prevention programmes as an integrated part of regular health examinations routinely performed within the OHS $[7,8]$, and early identification and interventions targeting problem drinking may even be considered more appropriate in OHS as compared to specialised health care [9]. In a Swedish study [1], it was discovered that OHS professionals were generally interested in gaining further training and knowledge regarding alcohol prevention.

Harmful alcohol consumption is a major risk factor for disease, disability and mortality, and has been identified as a causal agent in more than 200 disease and injury conditions $[10,11]$. According to the World Health Organization (WHO) [12], harmful alcohol consumption is related to approximately three million annual deaths globally. A recent study from the Global Burden of Disease project [13], based on data from 694 individual/ population-level sources and 592 prospective and retrospective studies, found that alcohol consumption is the leading risk factor for deaths and disability-adjusted lifeyears among the population aged 15 to 49 years (accounting for $3.8 \%$ of female deaths and $12.2 \%$ of male deaths). Despite robust evidence for adverse health consequences attributable to alcohol consumption, some studies have found a J-shaped relationship between alcohol and health, indicating that low to moderate consumption levels may carry certain health benefits. Moderate consumption has been inversely related to risk for certain cardiovascular diseases [14], diabetes type 2 [15] and certain mental health outcomes [16]. Such findings suggest that potential health benefits should be weighted against risks [17]. It is, however, somewhat unclear whether such results reflect true protective effects of alcohol or is a result of confounding [18, 19]. Nevertheless, decades of evidence implies that potential health benefits from alcohol will be outweighed by adverse consequences [11-13, 20]. Hence, efforts to reduce overall population-level alcohol consumption should be emphasised [13].

Alcohol is by far the most used psychoactive substance in the workforce [21]. One may discriminate between workforce alcohol consumption (overall consumption, regardless of context; [21]) and work-related alcohol consumption (consumption during working hours, shortly prior to work, or in contexts related to the work environment; [21-24]). Three out of four employees have been found to be overall regular drinkers, while approximately one out of ten has consumed alcohol during working hours [21]. In a Norwegian study, it was found that $43 \%$ of regular drinkers' consumption occurred in work-related settings [25]. Studies have estimated that one to three out of ten employees may benefit from alcohol prevention programmes [25-30]. Both in research and in policy guidelines, attempts have been made to distinguish between low-risk and risky drinking. Risky drinking has been defined as a pattern of drinking that increases the risk of social, legal, medical, occupational, domestic and economic problems [31]. Figure 1 presents a conceptual model for the relationships between alcohol consumption, drinking categories, prevention levels, risk levels and intervention recommendations.

Based on WHOs Alcohol Use Disorders Identification Test (AUDIT), an individual's drinking pattern may be measured on a scale ranging from 0 to 40 [31, 34]. A sum score of eight or higher is generally considered the threshold for risky drinking [31, 35]. Moreover, risky drinking is categorised into three risk levels (moderate risk: scores 8-15; high risk: scores 16-19; and dependence likely risk: scores 20-40) [31]. According to WHOs international intervention guidelines [33], low-risk drinkers should receive information about alcohol use and potential negative consequences, moderate-risk drinkers may benefit from low-cost interventions such 


Prevention level $^{\mathbf{a}}$
$\begin{aligned} & \text { Intervention } \\ & \text { recommendation }\end{aligned}$
Risk level $^{\mathfrak{c}}$
Drinking
category $^{\mathfrak{c}}$
AUDIT scale

\begin{tabular}{|c|c|c|c|}
\hline Primary & \multicolumn{2}{|c|}{ Secondary } & Tertiary \\
\hline $\begin{array}{c}\text { Alcohol } \\
\text { education }\end{array}$ & $\begin{array}{c}\text { Simple } \\
\text { advice }\end{array}$ & $\begin{array}{c}\text { Couns- } \\
\text { elling, } \\
\text { monit- } \\
\text { oring }\end{array}$ & Diagnostic evaluation \\
\hline Low & Moderate & High & Dependence likely \\
\hline $\begin{array}{c}\text { Low-risk } \\
\text { drinking }\end{array}$ & & Risky drinking \\
\hline & 10 & 20 & 30 \\
\hline
\end{tabular}

Fig. 1 Conceptual model of the relationships between alcohol consumption, drinking categories, risk levels, intervention recommendations and



as simple advice, high-risk drinkers should receive brief counselling and consecutive monitoring, while those with likely alcohol dependence should be referred to further diagnostic evaluation. In accordance with Coohey and Marsh's [32] conceptualisations of prevention levels, low-risk drinking employees constitute the target group for primary prevention activities, i.e., activities aimed at preventing an undesirable end-state (alcohol-related problems) before it occurs (or aimed at maintaining lowrisk drinking as a desirable state). Secondary prevention activities target individuals experiencing the early phases of the undesirable end-state (employees with moderate to high risk), while tertiary prevention is focused on employees with high to dependence likely risk [32].

Employees' alcohol consumption carries substantial societal costs. Productivity impairments associated with alcohol consumption comprise both not being at work (sick leave/absenteeism) as well as being at work but functioning sub-optimally (presenteeism). A recent literature review [36] found evidence to support an association between employees' alcohol consumption and short-term as well as long-term sick leave, across socioeconomic status and gender. On a population level, Scandinavian time-series studies have linked increased alcohol consumption to increased sick leave. Based on alcohol sales in Sweden, it was estimated that a monthly increase of one decilitre pure alcohol per inhabitant was associated with 2-2.5 more long-term sick leave spells per 10,000 inhabitants [37], while an annual increase of 3.5 decilitres pure alcohol per inhabitant has been linked to an annual increase of 1.6 million sick leave days in the Swedish population [38]. A relationship between employees' alcohol consumption and presenteeism (reduced on-the-job performance) has been demonstrated in several studies, e.g., in samples of American manufacturer employees [39], Finnish employees with multisite pain [40], Japanese community workers [41], and Norwegian employees in various occupations [42], implying that higher levels of alcohol consumption are associated with higher levels of work impairments. A Norwegian study [43] suggested that negative workplace consequences (e.g., safety and psychosocial issues) may occur even though the overall prevalence of alcohol-related abseenteeism and presenteeism may be quite low.

In addiction diseases, prevention is always of benefit. Alcohol prevention programmes targeting employees comprise a variety of intervention approaches on individual as well as an organisational level. According to Frone [21], they can be described as "interventions aimed at changing environmental, cultural, social, or personal factors in an effort (a) to keep individuals from abusing alcohol ( ...) and (b) to avert adverse work outcomes" (p. 143), for instance in the form of workplace health promotion programmes or drug testing. Although evidence is somewhat mixed, certain intervention approaches (e.g., brief interventions consisting of one to four consultations) have demonstrated promising results [44-47]. Implementation of alcohol prevention programmes has, however, proved difficult [48], suggesting that providing health professionals with research evidence and/or clinical guidelines may not be sufficient. Rather, evidence must be combined with implementation strategies aimed at providing health care professionals with encouragement and skills necessary to change established routines [49].

Implementation of brief alcohol prevention programmes has mainly been studied in primary care settings. Barry et al. [48] found that lack of time was the most important barrier to implementation. In a review of qualitative evidence [50], it was concluded that successful implementation is dependent on adequate financial and managerial support combined with workload reduction and training opportunities for health care professionals. In a sample of nurses working with hospitalised patients, lack of alcohol-related knowledge and skills, concerns about negative patient reactions and logistic issues (e.g., lack of time) were found to be salient anticipated barriers to implementation of alcohol prevention programmes [51]. Similarly, Babor et al. [52] concluded that lack of time, staff turnover and competing priorities were associated with lower alcohol prevention activity. 
Research related to OHS practice is limited, and research on alcohol prevention in the OHS is particularly sparse $[1,9,53-55]$. There is a need for further research on alcohol prevention in the OHS and on OHS professionals' potential role in increased prevention of alcohol problems [1]. In order to develop strategies aimed at enabling implementation of alcohol prevention programmes in the OHS, it is pivotal to gain knowledge about which barrier domains should be targeted. Implementation barriers may originate from and reside within different domains or contexts, such as the OHS' organisation itself (e.g., resources, time, workload, and competence/ training), or factors external to the OHS' organisation (e.g., employers'/clients' interest in focusing on employees' alcohol consumption, individual factors relating to OHS professionals' or employers'/clients' personal attitudes). Different barrier domains may require different implementation strategies and, moreover, different barrier domains may relate dissimilarly to working with different alcohol risk groups (e.g., primary, secondary and tertiary prevention activities). Hence, there is a need for studies investigating relationships between alcohol prevention activity and implementation barriers, i.e., for studies that explore associations beyond merely asking OHS professionals to rate which implementation barriers they perceive to be most salient. The present study adds to existing literature by providing updated knowledge on a rather under-researched topic, by generating knowledge on associations between implementation barriers and alcohol prevention activity, not merely on which and to what extent professionals perceive barriers, and by recognising that relationships between implementation barriers and prevention activity may vary according to alcohol risk level.

The primary aims of this study were to explore current practices of alcohol prevention targeting employees in occupational health settings, and examine whether and which perceived implementation barriers were associated with alcohol prevention activity. The secondary aim was to explore whether implementation barriers were differentially associated with primary, secondary and tertiary prevention activities.

\section{Methods}

\section{Design and setting}

The present study was designed as a cross-sectional survey as part of the Norwegian national WIRUS-project (Workplace Interventions preventing Risky Use of alcohol and Sick leave). Other results from the WIRUSproject are published elsewhere [24, 29, 42]. The study was conducted in 2018 among 357 health care professionals in 69 OHS units in Norway. OHS in Norway is regulated by the Working Environment Act [56] and OHS' are accredited by the Norwegian Labour Inspection
Authority, based on having at least three OHS professionals with expertise in the field of systematic health, safety and environmental (HSE) work (systematic activities undertaken in order to secure and improve the work environment), such as occupational hygiene and medicine, ergonomics and psychosocial work environment [3]. Systematic HSE work constitutes an interdisciplinary field, and the most frequent educational backgrounds among OHS professionals in Norway are nursing, medicine and physical therapy [57]. The proportion of employees in the Norwegian workforce who has access to OHS coverage is approximately $60 \%$, which is somewhat higher than in the USA, but quite comparable to other European countries [2]. In Norway, Akan represents an organisation that plays a key role in handling issues related to alcohol, drugs, gaming and gambling among employees [58]. Exploration of the role of Akan is beyond the scope of this study.

\section{Data collection and sample}

Contact information for accredited OHS' was obtained from the Norwegian Labour Inspection Authority, and all 206 accredited OHS' were invited to participate in the study. Ninety-three (45.2\%) OHS' responded to the invitation. Twenty-four of the 93 responding units declined to participate, and 12 of these units provided the following reasons for declining the invitation: Nine units did not have capacity to participate in research due to high workload, two units declined due to being involved in reorganisation processes, and one unit perceived the study as irrelevant to them. Sixty-nine units $(74.2 \%$ of the responding OHS') agreed to participate and sent lists of contact information for all health care professionals in their OHS. OHS' from all geographical counties in Norway were represented in the study. Moreover, OHS' providing services for companies in all work divisions (based on Eurostat's classification of economic activities [59]) were represented. Electronic questionnaires were distributed to 601 OHS professionals. A total of 357 (59.4\%) responded, while $295(49.1 \%)$ responded on all relevant items (20.0\% males; $80.0 \%$ females), and thus constituted the study sample. Respondents' mean age was 49.1 years ( $S D=9.9$ years $)$ and, on average, they had 12.3 years of experience as OHS professionals $(S D=9.1$ years). A wide range of professions participated. Nurses (38.6\%), physical therapists (17.3\%), and physicians (13.9\%) were the most frequent professions. Study sample characteristics are presented in Table 1.

\section{Measures}

\section{Alcohol prevention activity}

Respondents were asked to rate, on a five-point Likert scale $(1=$ not at all; $2=$ to a small extent; $3=$ to some extent; $4=$ to a large extent; $5=$ to a very large extent), to what extent their OHS unit engages in alcohol 
Table 1 Characteristics of the study sample $(N=295)$

\begin{tabular}{llllll}
\hline & & & & \multicolumn{2}{c}{ Range } \\
\cline { 5 - 6 } Variable & $M$ & SD & Median & Min & Max \\
\hline Age (years) & 49.1 & 9.9 & 49.0 & 25.0 & 75.0 \\
OHS experience (years) & 12.3 & 9.1 & 10.0 & $<1.0$ & 39.0 \\
Variable & $n$ & & $\%$ & & \\
Gender & & & & & \\
Male & 59 & & 20.0 & \\
Female & 236 & & 80.0 & \\
Professional background & & & & \\
Occupational therapist & 8 & & 2.7 & \\
Nutritionist & 1 & & 0.3 & \\
Physical therapist & 51 & 17.3 & \\
Physician & 41 & 13.9 & \\
Psychologist & 6 & 2.0 & \\
Nurse & 114 & 38.6 & \\
Occupational hygienist & 23 & 7.8 & \\
Other & & 51 & 17.3 & \\
\hline
\end{tabular}

$M$ mean, $S D$ standard deviation; ${ }^{a}$ e.g., medical secretaries, engineers, educationalists/teachers, economists and social scientists

prevention targeting employees, separately for three prevention levels (primary prevention, targeting low-risk drinkers; secondary prevention, targeting moderate to high-risk drinkers; tertiary prevention, targeting high to dependence likely-drinkers). A sum score for overall alcohol prevention activity was computed by combining the scores for activities on all three prevention levels (potential range $=1-15$ ). Categorisations of risk levels were based on WHO guidelines [31] (see Fig. 1).

\section{Perceived barriers to implementation of alcohol prevention programmes}

On a visual analogue scale ranging from 1 (to a very small extent) to 11 (to a very large extent), respondents were asked to rate the extent to which they perceived the following seven factors as barriers to implementation of alcohol prevention programmes in the OHS: (i) "alcohol is a personal/private matter"; (ii) "companies are not interested in employees' alcohol consumption"; (iii) "companies counteract programmes targeting their employees' alcohol consumption"; (iv) "lack of knowledge on the importance of alcohol prevention among OHS professionals"; (v) "lack of knowledge on how to conduct alcohol prevention programmes among OHS professionals"; (vi) "lack of time and/or resources"; and (vii) "others than the OHS are responsible for treating/intervening against employees' alcohol consumption".

The implementation barrier items were developed as part of the WIRUS-project, based on findings from previous research studying implementation of alcoholpreventive efforts in primary care settings [48, 50-52], and on three qualitative interview panels where nine OHS professionals were openly asked about barriers and facilitators for working with alcohol prevention in occupational health settings. Qualitative interview data was thematically analysed, resulting in categories corresponding to the seven implementation barrier items.

The implementation barrier items were subjected to an exploratory factor analysis (maximum likelihood approach with oblique rotation), resulting in a simple two-factor solution. The first factor (OHS competence/ time/resources) contained barriers concerning OHS' competence and resources (items iv; v; vi). The second factor (employer/employee barriers) consisted of barriers concerning employers and employees (items i; ii; iii; vii). Factor structure and internal consistency for the implementation barrier items are presented in Additional file 1.

\section{Covariates}

Respondents' perceptions of whether employees' alcohol consumption may be characterised as a public health challenge (challenge perception) were measured with a five-point Likert scale ranging from 1 (no, not at all) to 5 (yes, to a very large extent). Respondents' personal attitudes toward alcohol and work-related drinking (drinking social norms) were measured with the Drinking Norms Scale [60] (mean score of seven items; low score $=$ restrictive attitudes, high score $=$ liberal attitudes) . Frequency of alcohol cases (how often the OHS professional typically works with alcohol-related cases) was measured on a seven-point Likert scale $(1=$ never; $2=$ less than yearly; $3=$ yearly; $4=$ less than monthly; $5=$ monthly; $6=$ weekly; $7=$ daily). To what extent respondents believed OHS' should focus on alcohol prevention targeting employees (attitudes towards increasing alcohol prevention activity) was measured on a Likert scale $(1=$ considerably less than today; $2=$ less than today; $3=$ same as today; $4=$ more than today; $5=$ considerably more than today), with the addition of a neutral category of "unsure". Respondents also reported their age (years), gender (male; female), OHS experience (years) and professional background (occupational therapist; nutritionist; physical therapist; physician; psychologist; nurse; occupational hygienist; other).

\section{Analysis}

Descriptive statistics were utilised to analyse OHS professionals' perceptions of employee alcohol consumption as a public health challenge, how often they typically work with alcohol-related cases, perceived implementation barriers, and the OHS' alcohol prevention activity. One-way analysis of variance (ANOVA) was applied to explore whether frequency of working with alcoholrelated issues differed according to professional background. Differences between alcohol prevention activity 
on different prevention levels were tested by means of paired samples t-tests. Multivariate linear regression analyses were used to investigate whether and how OHS' alcohol prevention activity was associated with perceived implementation barriers. In order to allow meaningful comparisons between independent (predictor) variables, results from regression analyses were expressed in terms of standardised coefficients $(\beta)$. Statistical procedures were utilised based on sample size and exploration of whether specific tests' assumptions were appropriately met (e.g., the normality of data were tested by inspection of histograms, standardised residual plots, normal and detrended normal q-q plots). All statistical analyses were performed with IBM SPSS version 24. Significant results were defined as $p<.05$.

\section{Ethics}

OHS' and respondents were informed about the study's aim, assured confidentiality and that participation was voluntary. Written informed consent was obtained from all respondents. The study was approved by the Norwegian Centre for Research Data (NSD; reference no. 58038). The study was carried out in accordance with relevant guidelines and regulations.

\section{Results}

\section{Current practices of alcohol prevention}

Eight out of ten (80.4\%) OHS professionals agreed that employees' alcohol consumption constitute a public health challenge (17.3\% disagreed; $2.4 \%$ were unsure). However, seven out of ten (69.5\%) reported that they typically worked with alcohol-related cases less than monthly $(21.7 \%$ on a monthly basis; $8.8 \%$ on a weekly basis). Those who, to some extent, did work with alcohol cases did not differ from those who never worked with alcohol cases with regard to perception of OHS alcohol prevention activity and perception of implementation barriers (see Additional file 2: Table S2, 1). The reported frequency of working with alcohol-related cases differed significantly according to professional background $(F[2$, $\left.287]=12.4, p=<.001, \eta^{2}=0.2\right)$. Alcohol-related issues were primarily handled by physicians $(M=4.4 ; S D=1.1)$, psychologists $(M=4.3 ; S D=1.4)$ and nurses $(M=4.0$; $S D=1.4$ ), with a mean case frequency corresponding to between "less than monthly" and "monthly". Occupational therapists $(M=2.9 ; S D=1.7)$, physical therapists $(M=2.7 ; S D=1.5)$, and occupational hygienists $(M=1.9$; $S D=1.1$ ) were to a smaller extent involved in alcohol prevention, with a mean case frequency corresponding to between "less than yearly" and "yearly".

Overall, alcohol prevention activity were quite limited within the OHS' (only one out of ten OHS professionals worked with alcohol-related cases on a weekly basis). In their prevention activities, OHS' were most focused on tertiary prevention $(M=3.3 ; S D=0.8)$, followed by secondary prevention $(M=2.9 ; S D=0.7)$ and primary prevention $(M=2.8 ; S D=0.8)$. The difference between tertiary and primary activities was statistically significant, $\mathrm{t}(294)=8.9, p=<.001$. Similarly, the difference between tertiary and secondary activities was significant, $\mathrm{t}$ (294) $=10.0, p=<.001$. The difference between primary and secondary activities was not significant, $\mathrm{t}(294)=-1.4$, $p=.17$. OHS' alcohol prevention activity, according to prevention level and differences between levels, are presented in Table 2.

Almost seven out of ten (67.1\%) OHS professionals agreed that OHS' should focus more on alcohol prevention targeting employees (12.3\% disagreed; $20.3 \%$ were unsure).

\section{Implementation barriers and associations with prevention activity}

When asked which barriers to alcohol prevention in the workplace were perceived as most salient, OHS professionals focused on alcohol being a personal/private matter $(M=6.9 ; S D=2.9)$, and lack of employer interest in targeting their employees' alcohol consumption $(M=6.1$; $S D=2.7)$. An implementation barrier importance ranking is presented in Fig. 2.

Results from analyses of associations between perceived implementation barriers and alcohol prevention activity are presented in Table 3.

Barriers concerning OHS competence, time and resources demonstrated statistical significant associations with alcohol prevention activity, both overall $(\beta=-0.22$; $p=.001)$ and across all prevention levels. All associations were negative, implying that higher levels of perceived barriers were associated with lower reported prevention activity. With regard to specific prevention levels, OHS competence and resources were most strongly associated with primary prevention activities $(\beta=-0.20 ; p=.002)$, followed by tertiary $(\beta=-0.17 ; p=.008)$ and secondary prevention activities $(\beta=-0.14 ; p=.034)$. Reported

Table 2 Alcohol prevention activity according to prevention level, and matrix of differences between prevention levels $(N=295)$

\begin{tabular}{lll}
\hline & $\begin{array}{l}\text { Primary activities } \\
(M=2.8 ; S D=0.8)\end{array}$ & $\begin{array}{l}\text { Secondary activities } \\
(M=2.9 ; S D=0.7)\end{array}$ \\
\hline $\begin{array}{ll}\text { Primary activities } \\
(M=2.8 ; S D=0.8)\end{array}$ & - & $\begin{array}{l}M_{\text {diff }}=0.1^{\mathrm{ns}} \\
p=.173\end{array}$ \\
& & $\mathrm{t}(294)=-1.4$ \\
Secondary activities & $M_{\text {diff }}=0.1^{\mathrm{ns}}$ & - \\
$(M=2.9 ; S D=0.7)$ & $p=.173$ & \\
$\mathrm{t}(294)=-1.4$ & \\
Tertiary activities & $M_{\text {diff }}=0.5^{*}$ & $M_{\text {diff }}=0.5^{*}$ \\
$(M=3.3 ; S D=0.8)$ & $p=<.001$ & $p=<.001$ \\
& $\mathrm{t}(294)=8.9$ & $\mathrm{t}(294)=10.0$
\end{tabular}

Results from paired samples t-tests; $M$ mean, $S D$ standard deviation, $M_{\text {diff }}$ mean difference; * Statistically significant difference $(p<.05) ;{ }^{\text {ns }}$ Statistically non-significant difference $(p>.05)$ 




Fig. 2 Perceived barriers to implementing alcohol-preventive efforts in occupational health services $(N=295)$. Means and standard deviations. Visual analogue scales ranging from 1 (barrier to a very small extent) to 11 (barrier to a very large extent)

employer/employee barriers were not significantly associated with alcohol prevention activity.

\section{Discussion}

The primary aims of this study were to explore current practices of alcohol prevention targeting employees in occupational health settings, and examine whether and which perceived implementation barriers were associated with alcohol prevention activity. The majority of OHS professionals agreed that employees' alcohol consumption constitute a public health challenge (eight out of ten), and that OHS' should increase its prevention activity (seven out of ten). However, alcohol prevention activity was quite limited (seven out of ten worked with alcohol-related cases less than monthly, while only one out of ten did so on a weekly basis), and current activity

Table 3 Associations between perceived implementation barriers and alcohol prevention activity, overall and differentiated according to prevention level $(N=295)$

\begin{tabular}{lllll}
\hline Alcohol prevention activity \\
\hline Implementation & All groups & Primary & Secondary & Tertiary \\
barriers & $\beta$ ( $p$ value) & $\beta$ ( $p$ value) & $\beta$ ( $p$ value $)$ & $\beta$ ( $p$ value) \\
\hline OHS competence, $^{\text {OHS }}$ & $-0.22^{* *}$ & $-0.20^{* *}$ & $-0.14^{*}$ & $-0.17^{* *}$ \\
time, resources $^{\mathrm{a}}$ & $(.001)$ & $(.002)$ & $(.034)$ & $(.008)$ \\
Employer, employee $^{\mathrm{b}}$ & $-0.03^{\mathrm{ns}}$ & $-0.04^{\mathrm{ns}}$ & $-0.03^{\text {ns }}$ & $-0.01^{\text {ns }}$ \\
& $(.624)$ & $(.527)$ & $(.651)$ & $(.945)$ \\
\hline
\end{tabular}

Results from multivariate hierarchical linear regression analyses; All models are adjusted for gender, age, professional background, OHS experience and

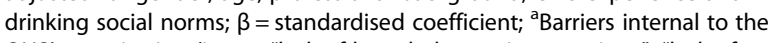
OHS' organisation (items: "lack of knowledge on interventions", "lack of knowledge on importance", "lack of time/resources"); "Barriers external to the OHS' organisation (items: "lack of employer interest", "employer resistance", "alcohol is a private/personal matter", "disclaimer of liability"); * $p<.05$;

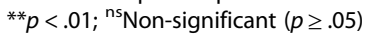

was significantly more focused on tertiary prevention than on primary and secondary prevention. These findings are consistent with previous research that has emphasised that the OHS should be more actively involved in alcohol prevention [1, 5, 6, 22].

Detrimental health and work performance outcomes related to alcohol consumption are well documented [10-13, 36-42], and reducing harmful use of alcohol has been defined as a keystone in sustainable development [12]. Promotion of employees' safety and health are emphasised in the aims of the OHS [1-3]. Hence, positive attitudes toward increased alcohol prevention in the OHS are not so surprising. Overall low prevention activity and favouring tertiary over primary and secondary prevention activities, may both be understood in terms of how the larger health care system is designed. The OHS do not operate in isolation from the health care system. Despite an increased awareness of benefits associated with preventive medicine and public health interventions, the health care system still tends to favour treatment (tertiary activities) over prevention (primary and secondary activities) [61]. According to Marvasti and Stafford [62], the health care system, designed in an era where handling infectious diseases was the major priority, is still today largerly characterised by an acute or reactive approach to health care. A system resting upon such a pathogenic paradigm [63] has been described as inexpedient in the current era where chronic and noncommunicable diseases (largely affected by lifestyle factors such as alcohol consumption) constitute the greatest threat to public health [62]. That OHS' in the present study were most focused on employees already experiencing adverse health consequences 
(tertiary prevention) was also reflected in the finding that alcohol-related cases were primary handled by physicians, psychologists and nurses.

Descriptively, OHS professionals reported alcohol being a private/personal matter for employees as the most salient barrier against alcohol prevention activity, followed by lack of employer interest in targeting their employees' alcohol consumption. Hence, when asked to identify and rank implementation barriers on a purely descriptive basis, our sample emphasised barriers related to employees and employers. However, analyses of associations between implementation barriers and alcohol prevention activity did display a quite different picture. Barriers concerning employers and employees (e.g., alcohol as a private/personal matter for employees, and lack of employer interest) were not significantly associated with alcohol prevention activity. In contrast, barriers internal to the OHS' organisation (competence, time and resources) demonstrated significant associations with activity on all prevention levels, implying that lack of knowledge on the importance of working with alcohol and training in administering alcohol prevention programmes, as well as lack of time and resources, were associated with low alcohol prevention activity. This finding is in line with research studying barriers against implementation of alcohol prevention programmes in primary care settings [48-52], and implies that successful implementation strategies should involve not only an emphasis on individual OHS professionals, units, employees and employers. Facilitation of successful implementation of alcohol prevention programmes in the OHS may hinge on emphasising both inner (organisational level) and outer (system level) contextual factors $[64,65]$ in order to ensure adequate training, time and resources.

The present study does not contain data that can enlighten the observed discrepancy between the descriptive and analytical findings regarding implementation barrier perception. Overall, OHS professionals were in agreement on the importance on working with alcohol prevention. At the same time, they did express quite limited prevention activity. It is possible to conceive that an organisational-level self-serving bias may have played a role in explaining why the main barriers were attributed externally (to employees and employers) rather than to the OHS' themselves. Self-protective attributional strategies is considered normal cross-cultural social-psychological phenomena [66, 67], and have also been identified within organisations [68]. The identified discrepancy does underscore the importance of studying implementation barriers beyond merely asking respondents to rate which barriers they perceive to be most salient.

The secondary aim of this study was to examine whether implementation barriers were differentially associated with primary, secondary and tertiary prevention activities. Results showed that implementation barriers were similarly associated with alcohol prevention activity on all three levels (i.e., that internal OHS barriers were related to prevention activity while external barriers were not). Hence, we found no fundamental reason to assume that different barriers apply when working on different prevention levels. Adequate training, resources and time stand out as important priorities in order to increase the implementation of alcohol prevention programmes in the OHS, regardless of whether they target individuals within the frames of primary, secondary or tertiary prevention.

\section{Methodological considerations}

The present study has some limitations. Conducted within a cross-sectional design, exploration of causal relationships was not possible in this study. The aims were, however, related to investigating current practices and associations between variables. Thus, a crosssectional design was deemed appropriate.

Results are based on data from 295 OHS professionals in 67 different OHS'. Of the 206 OHS' contacted, 113 did not respond to the invitation and 24 declined to participate. In order to explore possible selection bias more thoroughly we have, on an organisational level, compared data from the included OHS' with a representative sample of OHS' included in a Norwegian official evaluation from 2016 [57] (see Additional file 3: Table S3, 1). With the exception of an overrepresentation of physical therapists in our sample (17.3 versus $9.4 \%$, $p<.05)$, distributions of professional background were not significantly different. OHS' size (number of employees) and number of employers served by the OHS' were not significantly different, with the exception of a few more OHS' in our sample serving between 2 and 49 companies $(28.8$ versus $13.0 \%, p<.05)$. OHS' from all geographical counties in Norway, providing services for companies across work divisions, were represented in this study. On an individual level, 59.4\% $(n=357)$ responded to the questionnaire, while $49.1 \%(n=295)$ were included in the study as a result of responding on all relevant items. Of those 62 not responding on all relevant items, 57 did respond to the sociodemographic items. With the exception of these 57 non-responders having somewhat shorter OHS experience than the study sample (median 7.0 versus 10.0 years, $p<.05$ ), the non-responders did not differ significantly with regard to age, gender or professional background (see Additional file 3: Table S3, 2). The gender distribution was quite skewed in this study (males: $20.0 \%$; females $80: 0 \%$ ) but does correspond with the actual gender distribution among employees in health and social services in Norway (males: 19.0\%; females: 81\%) [69]. Moreover, 
male and female OHS professionals in our sample did not differ with regard to perception of $\mathrm{OHS}$ alcohol prevention activity and implementation barriers (see Additional file 2: Table S2, 2). Although we do not have reasons to believe that our sample was substantially non-representative, selection bias may constitute a possible limitation for this study. Hence, generalisations should be made with some caution.

The sample size was deemed satisfactory for analysing associations between variables as a result of well exceeding a recommended ratio of 15 participants per predictor variable [70], as well as exceeding the required size according to the formula $N>50+(8 \times n u m b e r$ of predictors) [71].

In order to avoid losing statistical power, some OHS professionals who reported not to work with alcoholrelated cases $(n=42)$ were included in the analyses, which may be perceived as a potential limitation. However, a series of additional tests did reveal that those professionals who did work with alcohol cases did not differ significantly from those who never worked with alcohol cases with regard to perception of OHS alcoholpreventive efforts and perception of implementation barriers (see Additional file 2: Table S2, 1).

Alcohol prevention activity and implementation barriers were measured by means of items developed particularly for the present study, which may be a limitation insofar that the instruments have yet to be validated. However, responses on all items were provided in the format of well-established response scales (Likert scales and Visual Analogue Scales). Moreover, the implementation barrier items were based on previous research as well as results from three qualitative focus group interviews with OHS professionals.

\section{Implications}

The present study implies that current practices of primary and secondary alcohol prevention activities in the OHS are quite limited. This seems particularly true for primary prevention activities. Our identification of significant associations between implementation barriers and alcohol prevention activity across all prevention levels, and the fact that barriers were most strongly associated with primary prevention activities, imply that (i) an increase in overall alcohol prevention activity, and (ii) a shift from mainly focusing on tertiary activities to an increased emphasis on general health promotion and early intervention (primary and secondary activities), may both be dependent on adequate training of OHS professionals as well as allocation of time and resources. Our findings suggest that strategies aimed at enabling implementation of alcohol prevention programmes in the OHS should place an emphasis on targeting barriers relating to the OHS organisation itself, and should take both organisational-level and system-level factors into consideration.

\section{Conclusions}

Alcohol consumption is associated with detrimental health and work performance outcomes, and occupational health settings may be particularly serviceable for alcohol prevention programmes targeting employees. However, this study found that the OHS infrequently engage in primary and secondary alcohol prevention activities. Factors internal to the OHS emerged as barriers against primary, secondary and tertiarty prevention activity. By ensuring adequate training, time and resources in the OHS, one may release an abeyant asset for preventing alcohol problems among employees, and thus contribute to remedy a major public health issue.

The relationship between implementation barriers and alcohol prevention activity in the OHS should be studied more thoroughly, preferably by means of longitudinal designs that enable exploration of causal mechanisms, and with studies investigating implementation processes in OHS related to specific alcohol prevention programmes (such as face-to-face interventions versus digital/webbased interventions). Moreover, future research would also benefit from exploring facilitating factors as well as implementation barriers.

\section{Additional files}

Additional file 1: Factor structure and internal consistency for the implementation barrier items. (XML 7 kb) (PDF 287 kb)

Additional file 2: Mann-Whitney $U$ tests for possible differences between professionals who worked with alcohol cases and those who did not, and between male and female OHS professionals. (PDF $22 \mathrm{~kb}$ )

Additional file 3: Study selection analyses. (PDF $304 \mathrm{~kb}$ )

\section{Abbreviations}

ANOVA: Analysis of variance; b: unstandardised regression coefficient; HSE: systematic health, safety and environmental work; $M$ : mean; N: sample size; NSD: Norwegian centre for research data; OHS: Occupational health services; $p$ : probability value; SD: Standard deviation; WHO: World Health Organization; WIRUS: Workplace Interventions preventing Risky Use of alcohol and Sick leave; $\beta$ : standardised regression coefficient

\section{Acknowledgements}

Not applicable.

\section{Authors' contributions}

RWA is the principal investigator and project manager of the WIRUS project. The WIRUS OHS study was designed by MMT and RWA, including questionnaire development. MMT recruited $\mathrm{OHS}^{\prime}$, analysed the data, and drafted the manuscript. JCS, IK, IJ and RWA provided scientific input to the different drafts and provided data interpretation. All authors made critical revisions and provided intellectual content to the manuscript, approved the final version to be published, and agreed to be accountable for all aspects of this work. 


\section{Funding}

This study is funded by the Norwegian Directorate of Health and the Research Council of Norway. The funding bodies had no role in the design of the study, nor in data collection, analysis or data interpretation.

\section{Availability of data and materials}

Data from the WIRUS OHS study are available from the project owner (University of Stavanger, Faculty of Health Sciences, Department of Public Health, Research group Societal Participation in School and Work) by principal investigator and project manager Randi Wågø Aas on reasonable request.

\section{Ethics approval and consent to participate}

The study was approved by the Norwegian centre for research data (NSD; reference no. 58038). Written informed consent was obtained from all participants.

\section{Consent for publication}

Not applicable.

\section{Competing interests}

The authors declare that they have no competing interests.

\section{Author details}

${ }^{1}$ Department of Occupational Therapy, Prosthetics and Orthotics, Faculty of Health Sciences, OsloMet - Oslo Metropolitan University, PO box 4 St. Olavs plass, NO-0130 Oslo, Norway. ${ }^{2}$ Presenter - Making Sense of Science, PO box 8118, NO-4068 Stavanger, Norway. ${ }^{3}$ Department of Health Promotion, Norwegian Institute of Public Health, PO box 973, NO-5808 Bergen, Norway. ${ }^{4}$ Center for Alcohol \& Drug Research, Stavanger University Hospital, PO box 8100, NO-4068 Stavanger, Norway. ${ }^{5}$ Department of Public Health, Faculty of Health Sciences, University of Stavanger, PO box 8600, Forus, NO-4036 Stavanger, Norway. ${ }^{6}$ National Advisory Unit on Rehabilitation in Rheumatology, Diakonhjemmet Hospital, PO box 23, Vindern, NO-0319 Oslo, Norway. ${ }^{7}$ Institute of Environmental Medicine, Division of Intervention and Implementation Research for Worker Health, Karolinska Institutet, SE-171 77 Stockholm, Sweden.

\section{Received: 22 February 2019 Accepted: 18 June 2019}

\section{Published online: 26 June 2019}

\section{References}

1. Holmqvist M, Hermansson U, Nilsen P. Towards increased alcohol intervention activity in Swedish occupational health services. Int J Occup Med Env. 2008;21:179-87.

2. Rantanen J, Lehtinen S, Valenti A, lavicoli S. A global survey on occupational health services in selected international commission on occupational health (ICOH) member countries. BMC Public Health. 2017. https://doi.org/10.1186/ s12889-017-4800-z

3. Lie A, Bjørnstad O. Accreditation of occupational health services in Norway. Occup Med-C. 2015;65:722-4.

4. Ames GM, Grube JW, Moore RS. Social control and workplace drinking norms: a comparison of two organizational cultures. J Stud Alcohol. 2000;61:203-19.

5. Kuokkanen M, Heljälä L. Early identification and brief intervention for risky drinkers in Finnish occupational health services. Scand J Work Env Hea. 2005;1:35-7.

6. Richmond R, Wodak A, Bourne S, Heather N. Screening for unhealthy lifestyle factors in the workplace. Aust Nz J Publ Heal. 1998;22:324-31.

7. Hermansson U, Helander A, Huss A. Brandt L, Rönnberg S. The alcohol use disorders identification test (AUDIT) and carbohydrate-deficient transferrin (CDT) in a routine workplace health examination. Alcohol Clin Exp Res 2000; 24:180-187.

8. Hermansson U, Knutsson A, Rönnberg S, Brandt L. Feasibility of brief intervention in the workplace for the detection and treatment of excessive alcohol consumption. Int J Occup Env Heal. 1998;4:71-8.

9. Kääriäinen J, Sillanaukee P, Poutanen P, Seppä K. Opinions on alcoholrelated issues among professionals in primary, occupational, and specialized health care. Alcohol Alcoholism. 2001;36:141-6.

10. Lim SS, Vos T, Flaxman AD, et al. A comparative risk assessment of burden of disease and injury attributable to 67 risk factors and risk factor clusters in
21 regions, 1990-2010: a systematic analysis for the global burden of disease study 2010. Lancet. 2012;380:2224-60.

11. Wood AM, Kaptoge S, Butterworth AS, et al. Risk thresholds for alcohol consumption: combined analysis of individual-participant data for 599912 current drinkers in 83 prospective studies. Lancet. 2018;391:1513-23.

12. World Health Organization. Global status report on alcohol and health, 2018. Geneva: World Health Organization; 2018.

13. Griswold MG, Fullman N, Hawley C, et al. Alcohol use and burden for 195 countries and territories, 1990-2016: a systematic analysis for the global burden of disease study 2016. Lancet. 2018;392:1015-35.

14. Roerecke M, Rehm J. Alcohol consumption, drinking patterns, and ischemic heart disease: a narrative review of meta-analyses and a systematic review and meta-analysis of the impact of heavy drinking occasions on risk for moderate drinkers. BMC Med. 2014. https://doi.org/10.1186/s12916-014-0182-6.

15. Knott C, Bell S, Britton A. Alcohol consumption and the risk of type 2 diabetes: a systematic review and dose-response meta-analysis of more than 1.9 million individuals from 38 observational studies. Diabetes Care. 2015;38:1804-12.

16. Bellos S, Skapinakis P, Rai D, et al. Cross-cultural patterns of the association between varying levels of alcohol consumption and the common mental disorders of depression and anxiety: secondary analysis of the WHO collaborative study of psychological problems in general health care. Drug Alcohol Depen. 2013;133:825-31.

17. Milic J, Glisic M, Voortman T, et al. Menopause, ageing, and alcohol use disorders in women. Maturitas. 2018;111:100-9.

18. Grønbæk M. The positive and negative health effects of alcohol- and the public health implications. J Intern Med. 2009;265:407-20.

19. Skog OJ. Public health consequences of the J-curve hypothesis of alcohol problems. Addiction. 1996;91:325-37.

20. Rehm J, Gmel GE, Gmel G, et al. The relationship between different dimensions of alcohol use and the burden of disease - an update. Addiction. 2017;112:968-1001.

21. Frone MR. Alcohol and illicit drug use in the workforce and workplace. Washington, DC: American Psychological Association; 2013.

22. Ames GM, Grube JW, Moore RS. The relationship of drinking and hangovers to workplace problems: an empirical study. J Stud Alcohol. 1997;58:37-47.

23. Mangione TW, Howland J, Amick B, et al. Employee drinking practices and work performance. J Stud Alcohol. 1999;60:261-70.

24. Nordaune K, Skarpaas LS, Sagvaag H, et al. Who initiates and organises situations for work-related alcohol use? The WIRUS culture study. Scand J Public Healt. 2017:45:749-56.

25. Nesvåg S, Lie T. Rusmiddelbruk blant ansatte i norsk privat arbeidsliv [Drug use among employees in Norwegian private sector]. Nordisk Alkohol- og Narkotikatidsskrift. 2004;21:91-109.

26. Howland J, Mangione T, Kuhlthau K, et al. Work-site variation in managerial drinking. Addiction. 1996:91:1007-17.

27. Kawakami N, Harantani T, Hemmi T, Araki S. Prevalence and demographic correlates of alcohol-related problems in Japanese employees. Soc Psych Psych Epid. 1992;27:198-202.

28. Marchand A, Parent-Lamarche A, Blanc ME. Work and high-risk alcohol consumption in the Canadian workforce. Int J Env Res Pub He. 2011;8: 2696-705.

29. Thørrisen MM, Skogen JC, Aas RW. The associations between employees' risky drinking and sociodemographics, and implications for intervention needs. BMC Public Health. 2018. https://doi.org/10.1186/s12889-018-5660-x.

30. Webb GR, Redman S, Hennrikus D, Rostas JAP, Sanson-Fisher RW. The prevalence and sociodemographic correlates of high-risk and problem drinking at an industrial worksite. Brit J Addict. 1990;85:495-507.

31. Babor TF, Higgins-Biddle JC, Saunders JB, Monteiro MG. AUDIT: the alcohol use disorders identification test. Guidelines for use in primary health care. Geneva: World Health Organization; 2001.

32. Coohey C, Marsh JC. Promotion, prevention, and treatment: what are the differences? Res Social Work Prac. 1995:5:524-38.

33. Babor TF, Higgins-Biddle JC. Brief intervention for hazardous and harmful drinking: a manual for use in primary care. Geneva: World Health Organization; 2001.

34. Saunders JB, Aasland OG, Babor TF, de la Fuente JR, Grant M. Development of the alcohol use disorders identification test (AUDIT): WHO collaborative project on early detection of persons with harmful alcohol consumption-II. Addiction. 1993;88:791-804. 
35. de Meneses-Gaya C, Zuardi AW, Loureiro SR, Crippa JAS. Alcohol use disorders identification test (AUDIT): an updated systematic review of psychometric properties. Psychol Neurosci. 2009;2:83-97.

36. Schou L, Moan IS. Alcohol use-sickness absence association and the moderating role of gender and socioeconomic status: a literature review. Drug Alcohol Rev. 2016;35:158-69.

37. Lidwall U, Marklund S. Trends in long-term sickness absence in Sweden 1992-2008: the role of economic conditions, legislation, demography, work environment and alcohol consumption. Int J Soc Welf. 2011;20:167-79.

38. Andreasson S, Holder HD, Norström T, Österberg E, Rossow I. Estimates of harm associated with changes in Swedish alcohol policy: results from past and present estimates. Addiction. 2006;101:1096-105.

39. Kirkham HS, Clark BL, Bolas CA, et al. Which modifiable health risks are associated with changes in productivity costs? Popul Health Manag. 2015; 18:30-8

40. Pensola T, Haukka E, Kaila-Kangas L, Neupane S, Leino-Arjas P. Good work ability despite multisite musculoskeletal pain? A study among occupationally active Finns. Scand J Public Health. 2016;44:300-10.

41. Tsuchiya M, Kawakami N, Ono Y. Impact of mental disorders on work performance in a community sample of workers in Japan: the world mental health Japan survey 2002-2005. Psychiatry Res. 2012;198:140-5.

42. Aas RW, Haveraaen L, Sagvaag H, Thørrisen MM. The influence of alcohol consumption on sickness presenteeism and impaired daily activities. The WIRUS screening study. PLOS ONE. 2017. https://doi.org/10.1371/journal. pone.0186503.

43. Buvik K, Moan IS, Halkjelsvik T. Alcohol-related absence and presenteeism: beyond productivity loss. Int J Drug Policy. 2018:58:71-7.

44. Kaner EF, Beyer FR, Muirhead C, et al. Effectiveness of brief alcoho interventions in primary care populations. Cochrane Database Syst Rev. 2018. https://doi.org/10.1002/14651858.CD004148.pub4.

45. O'Donnell $P$, Anderson P, Newbury-Birch D, et al. The impact of brief alcohol interventions in primary healthcare: a systematic review of reviews. Alcohol Alcoholism. 2014;49:66-78.

46. Riper H, van Straten A, Keuken M, Smit F, Schippers G, Cuijpers P. Curbing problem drinking with personalized-feedback interventions. Am J Prev Med. 2009:36:247-55.

47. Schulte B, O'Donnell AJ, Kastner S, Schmidt CS, Schäfer I, Reimer J. Alcohol screening and brief intervention in workplace settings and social services: a comparison of literature. Frontiers in Psychiatry. 2014. https://doi.org/10. 3389/fpsyt.2014.00131.

48. Barry KL, Blow FC, Willenbring M, McCormick R, Brockmann LM, Visnic S. Use of alcohol screening and brief interventions in primary care settings: implementation and barriers. Subst Abus. 2004;25:27-36.

49. Kaner EF, Lock CA, McAvoy BR, Heather N, Gilvarry E. A RCT of three training and support strategies to encourage implementation of screening and brief alcohol intervention by general practitioners. Brit J Gen Pract. 1999:49:699-703.

50. Johnson M, Jackson R, Guillaume L, Meier P, Goyder E. Barriers and facilitators to implementing screening and brief intervention for alcohol misuse: a systematic review of qualitative evidence. J Public Health. 2011;33:412-21.

51. Broyles $L M$, Rodriguez KL, Sevick MA, Price PA, Gordon AJ. A qualitative study of anticipated barriers and facilitators to the implementation of nursedelivered alcohol screening, brief intervention, and referral to treatment for hospitalized patients in a veterans affairs medical center. Addict Sci Clin Pract. 2012. https://doi.org/10.1186/1940-0640-7-7.

52. Babor TF, Higgins-Biddle J, Dauser D, Higgins P, Burleson JA. Alcohol screening and brief intervention in primary care settings: implementation models and predictors. J Stud Alcohol. 2005;66:361-8.

53. Hulshof $C T$, Verbeek JH, van Dijk FJ, van der Weide WE, Braam IT. Evaluation research in occupational health services: general principles and a systematic review of empirical studies. Occup Environ Med. 1999:56:361-77.

54. Nilsson PM, Klasson EB, Nyberg P. Life-style intervention at worksite reduction of cardiovascular risk factors in a randomized study. Scand J Work Env Hea. 2001;27:57-62.

55. Verbeek J, Husman $K$, van Dijk F, Jauhiainen M, Pasternack I, Vainio $H$. Building an evidence base for occupational health interventions. Scand $J$ Work Env Hea. 2004;30:164-8.

56. Working environment act. Act relating to working environment, working hours and employment protection, etc. Oslo: Norwegian ministry of labour and social affairs; 2005.
57. Mandal R, Dyrstad K, Melby L, Midtgård T. Evaluering av bedriftshelsetjenesten i Norge [Evaluation of the occupational health services in Norway]. Oslo: Sintef; 2016.

58. Akan kompetansesenter. English information about Akan [cited 2019 May 28]. Available from: https://akan.no/english-information-about-akan/.

59. Eurostat. NACE rev. 2. Statistical classification of economic activities in the European community. Luxembourg: Eurostat; 2008.

60. Barrientos-Gutierrez T, Gimeno D, Mangione TW, Harrist RB, Amick BC Drinking social norms and drinking behaviours: a multilevel analysis of 137 workgroups in 16 worksites. Occup Environ Med. 2007;64:602-8.

61. Rheinberger CM, Herrera-Araujo D, Hammitt JK. The value of disease prevention vs treatment. J Health Econ. 2016;50:247-55.

62. Marvasti FF, Stafford RS. From sick care to health care - reengineering prevention into the U.S. system. New Engl J Med. 2012;367:889-91.

63. Fries CJ. Healing health care: from sick care towards salutogenic healing systems. Soc Theor Health. 2019. https://doi.org/10.1057/s41285-019-00103-2.

64. Harvey G, Kitson A. PARIHS revisited: from heuristic to integrated framework for the successful implementation of knowledge into practice. Implement Sci. 2016. https://doi.org/10.1186/s13012-016-0398-2.

65. Harvey G, Kitson A. PARIHS re-visited: introducing i-PARIHS. In: Harvey G, Kitson A, editors. Implementing evidence-based practice in health care: a facilitation guide. Oxon: Routledge; 2015. p. 25-46.

66. Fletcher GJO, Ward C. Attribution theory and processes: a cross-cultural perspective. In: Bond $\mathrm{MH}$, editor. The cross-cultural challenge to social psychology. Newbury Park: Sage; 1988. p. 230-44.

67. Hogg MA, Vaughan GM. Social psychology. 6 ed. Harlow: Pearson Education Limited; 2011

68. Gioia DA, Sims HP. Self-serving bias and actor-observer differences in organizations: an empirical analysis. J Appl Soc Pscyhol. 1985;15:547-63.

69. Statistics Norway. Sysselsatte per 4. kvartal, etter region, næring, kjønn, alder og år [Employees per 4th quarter, by region, industry, gender, age and year]. Oslo, Norway: Statistics Norway; [cited 2019 Feb 15]. Available from: https://www.ssb.no/statbank/table/07984/

70. Stevens J. Applied multivariate statistics for the social sciences. 3rd ed ed. Mahwah: Lawrence Erlbaum; 1996.

71. Tabachnick BG, Fidell LS. Using multivariate statistics. 6th ed. ed. Pearson Education: Boston; 2013

\section{Publisher's Note}

Springer Nature remains neutral with regard to jurisdictional claims in published maps and institutional affiliations.

Ready to submit your research? Choose BMC and benefit from:

- fast, convenient online submission

- thorough peer review by experienced researchers in your field

- rapid publication on acceptance

- support for research data, including large and complex data types

- gold Open Access which fosters wider collaboration and increased citations

- maximum visibility for your research: over $100 \mathrm{M}$ website views per year

At $\mathrm{BMC}$, research is always in progress.

Learn more biomedcentral.com/submission 